\title{
nature
}

\section{Risks and benefits of dual-use research}

\author{
Negotiations over a sensitive scientific publication that could be misused by bioterrorists highlight trouble \\ ahead unless appropriate guidelines are developed.
}

$C^{t}$ cientists, security experts and journals have done a great deal to face up to the risk of bioterrorism, but there is still considerable uncertainty over how to handle 'dual use' research with outcomes that might be used to do harm (see page 860). This fact is underscored by confusion about a paper on such research that was accepted for publication last month by the Proceedings of the National Academy of Sciences (PNAS).

The episode began on 25 May, when the journal announced that it would publish a paper by Lawrence Wein, a professor of management at the Stanford University Graduate School of Business, California. Working with a graduate student, Wein had constructed a model of a bioterrorist attack on the US milk supply. Stewart Simonson, assistant secretary for public health emergency preparedness at the US Department of Health and Human Services (HHS), was shown the paper by a reporter, who had obtained a copy under embargo. He promptly asked the National Academy of Sciences, which publishes the journal, not to release it.

Simonson's concern, which was shared by other officials, was that details of the paper could be helpful to terrorists. The National Academy agreed to delay publication of the paper and met with Simonson and other HHS officials on 7 June. As Nature went to press, the National Academy had not announced how it would move forward, but seemed indined to publish the paper essentially unmodified.

Both Wein and the journal were well aware of the sensitive nature of this paper. In fact, Wein briefed Simonson's office on the research last autumn, and Simonson says that he conveyed his concerns about the work to Wein at that time. Wein contradicts that statement, maintaining that the HHS never replied to his briefing. When Wein submitted his paper to PNAS, the journal sent it through two layers of review, as specified by many journals, including Nature, in 2003 - one for scientific accuracy and one for biosecurity. None of the reviewers opposed publication, and the editors concluded that the paper's potential to inform biosecurity efforts outweighed the risk of it giving a blueprint to terrorists. So the journal decided to publish.

Each of the parties to this dispute could have acted differently. For instance, the apparent breakdown in initial communication between Wein and the HHS implies a cursory approach to such a sensitive matter on both sides and a lack of a robust system for such alerts by responsible researchers.

The HHS did not fund Wein's work, and has never intervened in a publication in this fashion before. In doing so, however, it has raised the profile of the issue. The department might have accomplished more by working behind the scenes with Wein and the dairy industry to increase safety, instead of taking action against a journal. Much of the information in Wein's paper is readily available on the Internet anyway.

PNAS followed its normal procedures but was prudent to allow a brief delay to listen to the HHS. Having previously committed to the paper, in the absence of any significant new security risks being raised, it should now stick to its decision. But there will doubtless follow a broader debate on whether such papers should be submitted to, and accepted by, a high-profile scientific journal.

The greatest concern is in the need for clarity. It is important to develop clear guidelines about what research is considered sensitive, what is expected of researchers whose work produces dual-use outcomes, and how the government should in practice respond without losing the priceless virtues of open scientific scrutiny. Without such clarity, officials insensitive to those virtues may institute precautionary measures that reach far beyond what is appropriate. The US National Science Advisory Board for Biosecurity, which was set up a year ago by the US government to address such concerns, will hold its first meeting at the end of this month, and will need to act promptly.

\section{Save the people, too}

Conservationists must pay attention to the needs of local human, as well as animal, populations.

7 o have real passion for one's work is a wonderful thing. And there are few people more passionate than the biologists who strive to preserve biodiversity across the developing world. Many are prepared endure physical privations, infectious diseases, low pay and threats of violence, all in the name of conservation.

But passion can sometimes distort judgment. Just as starry-eyed lovers may be blind to one another's faults, a true believer in any cause can ignore uncomfortable facts that conflict with its goals. That is why the motivations and actions of conservation biologists who are working in Myanmar, with the blessing of its brutal military regime, merit dose scrutiny.

In the past, such scrutiny has been uncomfortable for some of the individuals concerned - most notably following the 1997 publication of an article in The Observer, a UK newspaper, entitled 'Save the rhino, kill the people.' This linked such venerable bodies as the Smithsonian Institution in Washington DC and the Wildlife Conservation Society, based in New York, with abuses of human rights in the southeast Asian nation formerly known as Burma.

The biologists who were singled out for criticism in that article argue, with good cause, that it misrepresented their efforts. And it is apparent from a News Feature on page 870 of this issue that they are working with clear consciences, despite having to engage on 